Provided for non-commercial research and education use. Not for reproduction, distribution or commercial use.

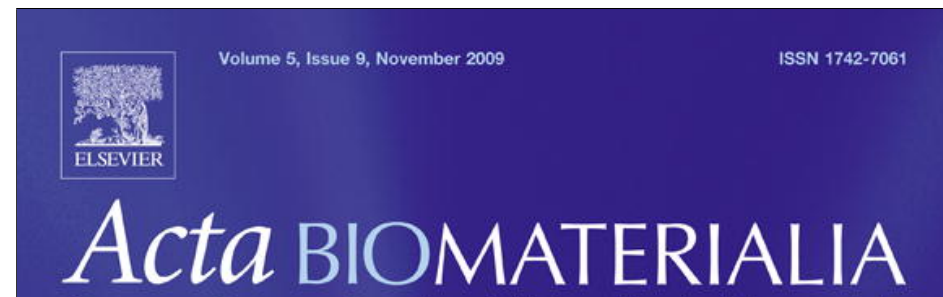

Structure-Property-Function Relationships in Biomaterials

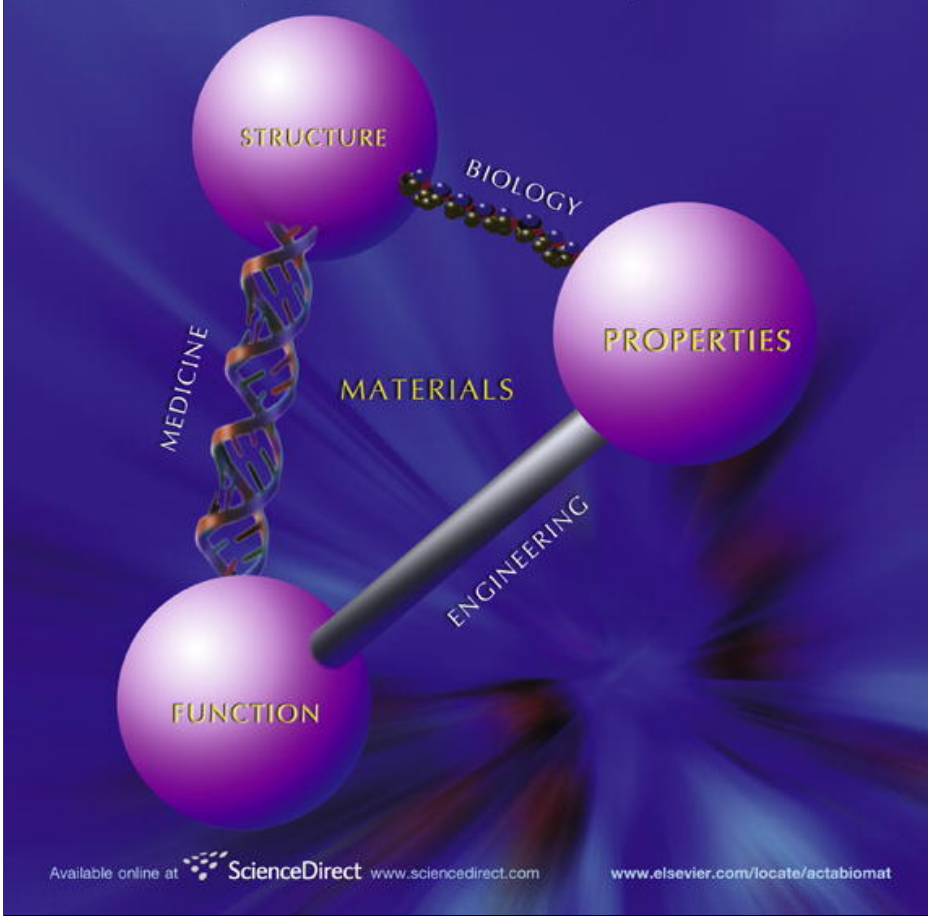

This article appeared in a journal published by Elsevier. The attached copy is furnished to the author for internal non-commercial research and education use, including for instruction at the authors institution and sharing with colleagues.

Other uses, including reproduction and distribution, or selling or licensing copies, or posting to personal, institutional or third party websites are prohibited.

In most cases authors are permitted to post their version of the article (e.g. in Word or Tex form) to their personal website or institutional repository. Authors requiring further information regarding Elsevier's archiving and manuscript policies are encouraged to visit:

http://www.elsevier.com/copyright 


\title{
Chitosan scaffolds incorporating lysozyme into CaP coatings produced by a biomimetic route: A novel concept for tissue engineering combining a self-regulated degradation system with in situ pore formation
}

\author{
Ana M. Martins, Rui C. Pereira, Isabel B. Leonor, Helena S. Azevedo, Rui L. Reis* \\ 3B's Research Group - Biomaterials, Biodegradables and Biomimetics, University of Minho, Headquarters of the European Institute of \\ Excellence on Tissue Engineering and Regenerative Medicine, AvePark, 4806-909 Taipas, Guimarães, Portugal \\ IBB - Institute for Biotechnology and Bioengineering, PT Government Associated Laboratory, Guimarães, Portugal
}

Received 27 October 2008; received in revised form 25 March 2009; accepted 19 May 2009

Available online 27 May 2009

\begin{abstract}
This study describes an innovative self-regulated degrading material with gradual in situ pore formation ability for bone tissue engineering applications. This approach is based on the incorporation of the lysozyme enzyme into calcium phosphate $(\mathrm{CaP})$ coatings, prepared on the surface of chitosan scaffolds by means of a biomimetic coating technique with the aim of controlling their degradation rate and subsequent formation of pores. However, because lysozyme has antibacterial properties, these coatings may act as a carrier for its sustained release, preventing infection upon implantation. In order to prove the concept of in situ pore formation, the coated scaffolds (with and without lysozyme) were incubated in two different solutions at different $\mathrm{pH}$ to simulate normal physiological conditions (pH 7.4) and inflammatory response ( $\mathrm{pH}$ 5). The weight loss and morphology of the scaffolds was monitored over time. At $\mathrm{pH} 7.4$, the scaffolds remained more stable than at $\mathrm{pH}$. The scaffolds incubated at $\mathrm{pH} 5$ showed a rapid decrease in their initial weight, and scanning electron microscopy imaging revealed the formation of a highly porous structure. Furthermore, evaluation of the activity of the incorporated lysozyme revealed that the enzyme was able to hydrolyse the peptidoglycan of the bacteria cell walls (as detected by the decrease in optical density with time), indicating that the enzyme remained active after being incorporated into the CaP coating.

(C) 2009 Published by Elsevier Ltd. on behalf of Acta Materialia Inc.
\end{abstract}

Keywords: Chitosan; Cap coatings; Lysozyme; Degradation; In situ pore formation

\section{Introduction}

A novel concept in tissue engineering which proposes in situ pore-forming scaffolds has been reported previously [1]. Chitosan has been considered a promising material for tissue engineering applications. It is a linear copolymer of

\footnotetext{
* Corresponding author. Address: 3B's Research Group-Biomaterials, Biodegradables and Biomimetics, University of Minho, Headquarters of the European Institute of Excellence on Tissue Engineering and Regenerative Medicine, AvePark, 4806-909 Taipas, Guimarães, Portugal. Tel.: +351 253 510902; fax: +351253510909.

E-mail address: rgreis@dep.uminho.pt (Rui L. Reis).
}

$\mathrm{N}$-acetyl-D-glucosamine and D-glucosamine, derived from chitin by a deacetylation reaction. The degree of deacetylation (DD) measures the percentage of glucosamine units in the polymer chain and influences its physicochemical properties such as solubility, crystallinity and swelling behavior, and its biological properties [2], namely osteogenesis enhancement [3]. The degradation kinetics appear to be inversely related to the DD [4]. It has been demonstrated that chitosan is degraded in vitro and in vivo by lysozyme $[4,5]$, an enzyme ubiquitous in the human body [6,7]. Lysozyme can attack cell wall polysaccharides of different bacterial species, especially Gram-positive bacteria, leading to rupture of the cell wall and killing of the micro-organism 
$[8,9]$. This study proposes the incorporation of the lysozyme enzyme into calcium phosphate $(\mathrm{CaP})$ coatings, prepared on the surface of chitosan scaffolds by means of a biomimetic coating technique, with the aim of controlling their degradation rate and subsequent formation of pores. Furthermore, since lysozyme has antibacterial properties, these coatings may act as a carrier for its sustained release, preventing infection upon implantation. An improvement in the osteoconductivity of implants has been achieved by coating their surfaces with $\mathrm{CaP}$ layers [10-12]. The biomimetic methodology for coating biomaterials with a bonelike apatite layer has been described in several publications [13-17]. This technique mimics natural biomineralization processes, involving controlled crystal nucleation and growth control over the phase of the mineral deposited [18]. The main advantage of the biomimetic methodology is the use of physiological conditions ( $\mathrm{pH} 7.4$ at $37^{\circ} \mathrm{C}$ ) simulating the manner in which apatite is formed in bone. Moreover, this technique allows the incorporation of proteins and bioactive agents into $\mathrm{CaP}$ coatings without compromising their activity [19-22]. An ideal material for the purpose of a temporary support for bone replacement should feature an adequate range of mechanical properties with convenient degradation kinetics, bone-bonding behavior and biocompatible performance [23].

In order to enhance the formation of pores in situ, chitosan scaffolds coated with CaP layers and lysozyme incorporated into the coatings were developed, presenting properties that promote degradation and osteoconductive potential. Lysozyme enzyme was incorporated into $\mathrm{CaP}$ coatings on the surface of chitosan scaffolds by means of a biomimetic route $[13,14,22]$. Moreover, $\mathrm{CaP}$ coatings enhance the osteoconductive properties of the chitosan scaffolds.

This study was designed to answer the following questions: Can a hydrolytic enzyme be incorporate at the surface of chitosan scaffolds without compromising its activity? Is it possible to develop a non-porous scaffold with in situ pore-forming ability? How many days does it takes to have a porous scaffold in situ fully interconnected simulating in vivo conditions?

\section{Materials and methods}

\subsection{Materials}

Chitosan with a DD of $92 \%$ and medium molecular weight was obtained from Sigma (St. Louis, USA). Bioglass $45 \mathrm{~S} 5$ with composition $45 \mathrm{SiO}_{2}, 24.5 \mathrm{CaO}, 24.5 \mathrm{Na}_{2} \mathrm{O}$ and $6.0 \mathrm{P}_{2} \mathrm{O}_{5}$ (in wt.\%) was supplied by NovaMin Technology Inc. (Alachua, FL).

\subsection{Preparation of chitosan scaffolds}

Chitosan scaffolds were prepared as previously described by Martins et al. [1]. Briefly, chitosan was dissolved in acetic acid $1 \%(\mathrm{v} / \mathrm{v})$ to obtain a $5 \%(\mathrm{w} / \mathrm{v})$ solution. Then, the solu- tion was cast into polyethylene moulds and frozen $\left(-18{ }^{\circ} \mathrm{C}\right)$ overnight. After that, they were immersed in a precipitation solution $\left(25 \% \mathrm{NaOH} 1 \mathrm{M}\right.$ and $\left.75 \% \mathrm{Na}_{2} \mathrm{SO}_{4} 0.5 \mathrm{M}\right)$ overnight, adapted from the method developed by Tuzlakoglu et al. [24]. After precipitation, the samples were washed several times with distilled water and dried at $37^{\circ} \mathrm{C}$.

\subsection{Preparation of CaP biomimetic coatings}

The method of preparing the CaP coatings was based on the methodology previously developed by Abe et al. [13] and adapted by Reis et al. [14,15], consisting in impregnation of the materials with bioactive glass called Bioglass $45 \mathrm{~S} 5$, followed by immersion in a simulated body fluid (SBF, $37^{\circ} \mathrm{C}, \mathrm{pH} 7.4$ ), presenting ionic concentrations similar to human blood plasma. Prior to the coating process, chitosan scaffolds were sterilized by ethylene oxide. Bioglass $45 \mathrm{~S} 5$ was sterilized by immersion in ethanol solution $(70 \% \mathrm{v} / \mathrm{v})$ and then dried inside the hood. All the subsequent work was performed under sterile conditions in a hood. Briefly, chitosan scaffolds were rolled in a wet bed of Bioglass 45S5. After that, the scaffolds were immersed in a 1.0 SBF solution, without (control) and with lysozyme $\left(1 \mathrm{~g} \mathrm{~L}^{-1}\right)$ from chicken egg white (Fluka, USA), for 7 days at $37^{\circ} \mathrm{C}$, a period known as the nucleation stage, which allows $\mathrm{CaP}$ nuclei formation. After the nucleation stage, all samples were washed with distilled water and immersed in a concentrated 1.5 SBF solution for 3, 7 and 14 days at $37^{\circ} \mathrm{C}$, in order to enhance $\mathrm{CaP}$ nuclei growth. All the solutions were sterilized by filtration prior to use. After each time period, chitosan scaffolds were washed with distilled water and dried until surface characterization was performed. The morphology of the CaP coatings obtained was analysed by scanning electron microscopy (SEM; Leica Cambridge S-360, UK). Prior to microstructure analysis, specimens were coated with gold using a Fisons Instruments Coater (Polaron SC 502, UK). In order to characterize the crystalline/amorphous nature of the films, thin-film X-ray diffraction (TF-XRD; Philips X'Pert MPD, The Netherlands) was used. Data collection was performed by the $2 \theta$ scan method with $1^{\circ}$ as the incident beam angle, using a $\mathrm{Cu} \mathrm{K} \alpha \mathrm{X}$-ray line and a scan speed of $0.05^{\circ} \mathrm{min}^{-1}$ in 20. In addition, infrared analysis (FTIR) of the coatings was performed in a Perkin-Elmer spectrometer (PerkinElmer 1600 series equipment, USA) to examine the chemical structure of the $\mathrm{CaP}$ biomimetic coatings obtained. Coatings were scraped from the chitosan scaffolds, mixed with $\mathrm{KBr}$ (Riedel-de Haën, Germany) and then formed into a disc in a press. All spectra were obtained between 4400 and $450 \mathrm{~cm}^{-1}$ at a resolution of $2 \mathrm{~cm}^{-1}$.

\subsection{Degradation studies}

In order to simulate in vivo conditions, degradation studies were carried out by incubating uncoated chitosan scaffolds and CaP-coated chitosan scaffolds, with and without incorporated lysozyme, in two different buffer solu- 
tions: (i) Tris- $\mathrm{HCl}$ buffer $(0.22 \mathrm{mM}, \mathrm{pH} 7.4)$ to simulate the normal $\mathrm{pH}$ found in human body; and (ii) citrate buffer $(1.0 \mathrm{mM}, \mathrm{pH} 5.0)$ to simulate the inflammatory response at $37^{\circ} \mathrm{C}$ for different periods of time. At the end of each degradation period, the samples were removed, washed with distilled water and dried for later calculation of weight loss (Eq. (1)). The morphology of the scaffolds after degradation was analysed by SEM.

Weight loss $(\%)=($ Initial weight

$$
\text { - Final weight)/Initial weight }
$$

\subsection{Determination of lysozyme activity in solution and released from the CaP coatings}

In order to evaluate the lysozyme activity and that released from the $\mathrm{CaP}$ coating at $\mathrm{pH} 5$ and $\mathrm{pH} 7.4$, the Micrococcus lysodeikticus assay was used. This assay is based on the ability of lysozyme to hydrolyse the cell wall fragments of bacteria. For determining the activity of released lysozyme, coated scaffolds with incorporated lysozyme were immersed in buffer solution ( $\mathrm{pH}$ 7.4) and incubated at $37^{\circ} \mathrm{C}$ for 30 days. The released lysozyme $(150 \mu \mathrm{L})$ was added to $100 \mu \mathrm{L}$ of Micrococcus lysodeikticus suspension (2.3 mg mL $\left.{ }^{-1}, \mathrm{pH} 7.4\right)$ in a 96-well plate. The decrease in turbidity at $37^{\circ} \mathrm{C}$ was measured at $450 \mathrm{~nm}$ (Microplate Reader, Synergy HT, BIO-TEK Instruments, Inc., USA) at 1-min intervals for $30 \mathrm{~min}$. The same procedure was used to determine the enzyme activity at $\mathrm{pH} 5$ and $\mathrm{pH}$ 7.4. For that, known enzyme concentrations were prepared in buffers at pH 5 and $\mathrm{pH} 7.4$ and added to the bacteria suspension in the same buffer. The initial kinetic rate (OD slope at $t=0$ ) was measured for each sample, and a standard curve (lysozyme activity vs lysozyme concentration) was constructed. The lysozyme activity released after 30 days was determined from the standard curve.

\subsection{Statistics}

Results of weight loss are expressed as mean \pm standard deviation with $n=3$ for each group. The statistical significance of differences was determined using Student's $t$-test multiple comparison procedure at a confidence interval of $95 \%(p<0.05)$.

\section{Results and discussion}

\subsection{Development of CaP biomimetic coatings}

Fig. 1 shows SEM images of the uncoated chitosan scaffold (Fig. 1A) and CaP-coated chitosan scaffolds after immersion in SBF solution in the presence (Fig. 1C and E) and absence (Fig. 1B and D) of lysozyme. At the nucleation stage, it is possible to observe for both conditions (with and without lysozyme) the formation of apatite nuclei (Fig. 1B and C). Lysozyme incorporation in the nucleation stage did not significantly affect the morphology of the coatings (Fig. 1C). In the first 7 days of the growth stage for both conditions, it is possible to observe that the size of $\mathrm{CaP}$ nuclei increased, forming a dense and compact $\mathrm{CaP}$ film. This means that immersion in SBF solution promotes the growth of the $\mathrm{CaP}$ layer over time. At higher magnifications, after 7 days of growth, the morphology of the coatings is similar in the presence and absence of lysozyme, demonstrating typical cauliflower morphology (Fig. 1D1 and E1). Lysozyme incorporation into the coatings did not affect the morphology and growth of the coatings as a function of immersion time.

Fig. 2A presents the IR spectra of $\mathrm{CaP}$ coatings with and without lysozyme (control) at nucleation stage. Analysis of $\mathrm{CaP}$ coatings in the absence of lysozyme shows the presence of phosphate $\left(\mathrm{PO}_{4}{ }^{3-}\right)$ groups (bands at 1055, 602 and $\left.556 \mathrm{~cm}^{-1}\right)$. Moreover, the presence of carbonate $\left(\mathrm{CO}_{3}{ }^{2-}\right)$ bands (1492 and $\left.1441 \mathrm{~cm}^{-1}\right)$ was detected. When lysozyme was added at the nucleation stage, the same phosphate and carbonate groups were also detected (Fig. 2A). In the spectrum of $\mathrm{CaP}$ coating with lysozyme, the appearance of an amide I band $\left(1656 \mathrm{~cm}^{-1}\right)$ was observed, indicating that lysozyme is incorporated in the coating. The amide I band represents the stretching vibrations of $\mathrm{C}=\mathrm{O}$ bonds in the backbone of the proteins $[22,25]$. FTIR spectra of both $\mathrm{CaP}$ coatings, with and without lysozyme, confirmed an apatite layer formation on the surface of the scaffolds, with similar composition of the major mineral component of the bone [26].

TF-XRD analyses were performed to determine whether the $\mathrm{CaP}$ coatings were crystalline or amorphous. Fig. 2B shows TF-XRD patterns of $\mathrm{CaP}$ coatings in the absence and presence of lysozyme. No crystalline peaks were detected for CaP-coated chitosan scaffolds with or without incorporated lysozyme at the nucleation stage (Fig. 2Bb and $\mathrm{Bc}$ ). After 7 days of growth, two characteristic peaks of hydroxyapatite are visible in the diffraction patterns of $\mathrm{CaP}$ coatings in the presence and absence of lysozyme, which are confirmed by comparison with an XRD pattern of standard hydroxyapatite (JCPDS 9-432) (Fig. 2Bd and Be). These TF-XRD patterns confirm the formation of an apatite layer owing to the presence of apatite peaks. However, the apatite formed appears to be mainly amorphous. These results together with FTIR spectra suggest that the mineral formed is a carbonate apatite mineral similar to the major mineral component of bone.

\subsection{Degradation studies}

The degradation behavior of the chitosan scaffolds developed (uncoated chitosan scaffolds, CaP-coated chitosan scaffolds with and without incorporated lysozyme) was investigated by incubation in buffer solutions for different periods of time. To simulate in vivo conditions and the ability of in situ pore formation, two different $\mathrm{pHs}$ were tested: $\mathrm{pH} 7.4$ to simulate normal physiological conditions; and $\mathrm{pH} 5$ to simulate inflammatory response. 

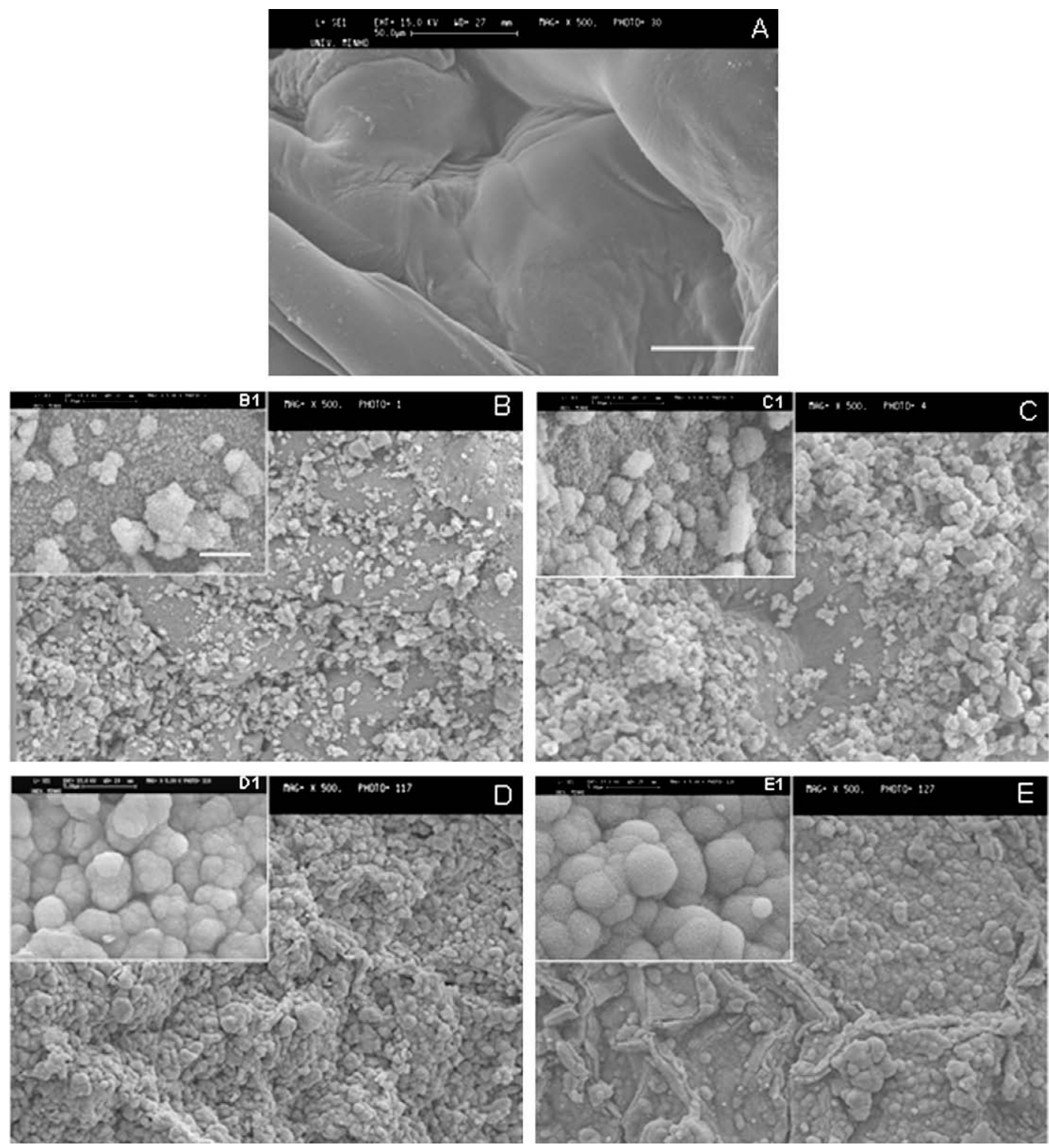

Fig. 1. SEM images of the surface of chitosan scaffolds (A) uncoated, (B and B1) coated with a CaP layer at nucleation stage and (D and D1) after 7 days in the growth stage, and $(\mathrm{C}$ and $\mathrm{C} 1)$ coated with $\mathrm{CaP}$ layer with incorporated lysozyme at nucleation stage and $(\mathrm{E}$ and $\mathrm{E} 1)$ after 7 days in the growth stage. The scale bar is $50 \mu \mathrm{m}$ for images $\mathrm{A}-\mathrm{E}$ and $5 \mu \mathrm{m}$ for images B1-E1.

On analysis of the weight loss profile at pH 7.4 (Fig. 3A), all scaffolds presented gradual weight loss as a function of degradation time. The lowest weight loss was observed for uncoated chitosan scaffolds, with almost $4 \%$ after 60 days. The corresponding SEM images show an increase in the surface roughness as a function of immersion time (Fig. 4D, G and $\mathrm{J}$ ). These observations are in accordance with weight loss results (Fig. 3A). The CaP-coated chitosan scaffolds presented a significant weight loss of $7.6 \pm 0.2 \%$ after 60 days (Fig. 3A). SEM images show several changes in the $\mathrm{CaP}$ coatings morphology after only 3 days of immersion at $\mathrm{pH}$ 7.4 , suggesting that the coatings may be gradually dissolved with time (Fig. 4E, H and K). CaP-coated chitosan scaffolds with incorporated lysozyme presented the highest weight loss compared with the other two conditions (uncoated chitosan and CaP-coated chitosan scaffolds), presenting a significant weight loss of $\sim 9 \%$ after 14 days, which slightly increases to $11.5 \pm 1.0 \%$ upon 60 days of immersion (Fig. 3A). Analysing SEM images (Fig. 4C, F, I and L), some differences between the coatings in Tris- $\mathrm{HCl} \mathrm{pH} 7.4$ were observed as a function of immersion time. However, these differences are not pronounced when compared with $\mathrm{CaP}$ coatings in the absence of lysozyme. Lysozyme seems to promote the degradation of chitosan scaffolds surfaces, as it is possible to observe the highest weight loss when lysozyme is present. These findings are corroborated by the results of enzyme activity that showed that the enzyme present on the coatings was still active after 30 days (Fig. 6A). Never- 

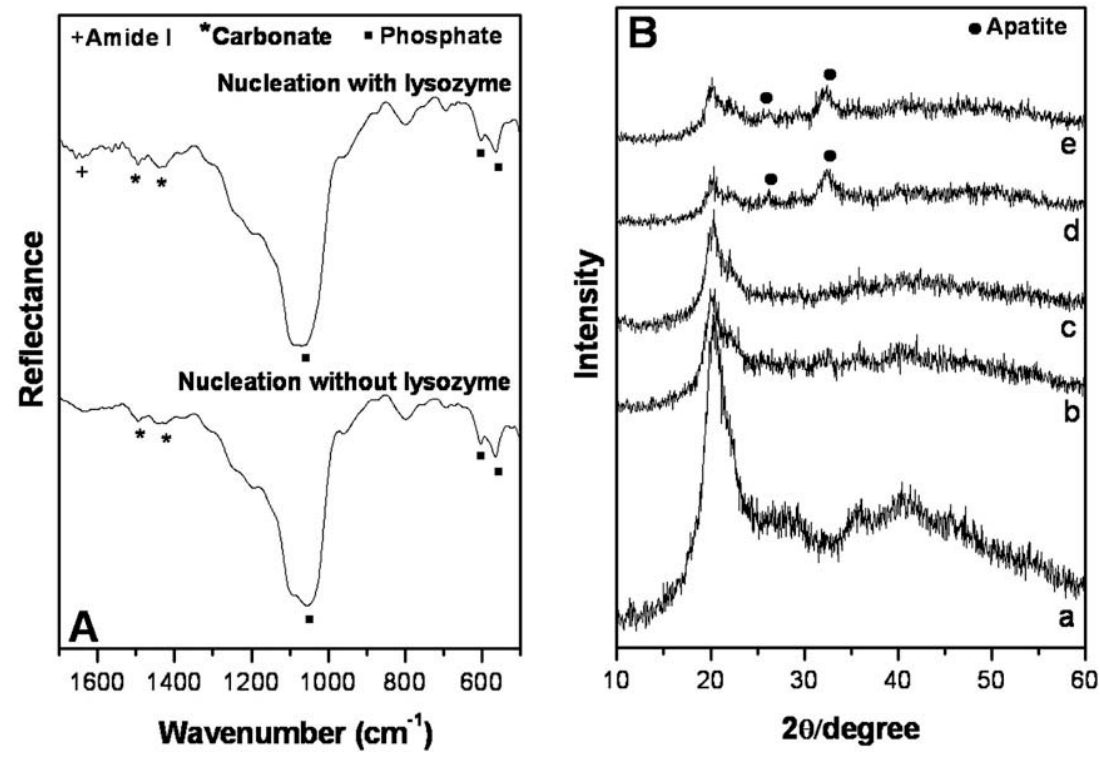

Fig. 2. (A) FTIR spectra of CaP coatings, with and without incorporated lysozyme at nucleation stage. (B) TF-XRD spectra of: (a) uncoated chitosan scaffolds; CaP-coated chitosan scaffolds at (b) nucleation stage and (d) after 7 days of growth; (c) CaP-coated chitosan with incorporated lysozyme at nucleation stage and (e) after 7 days of growth.
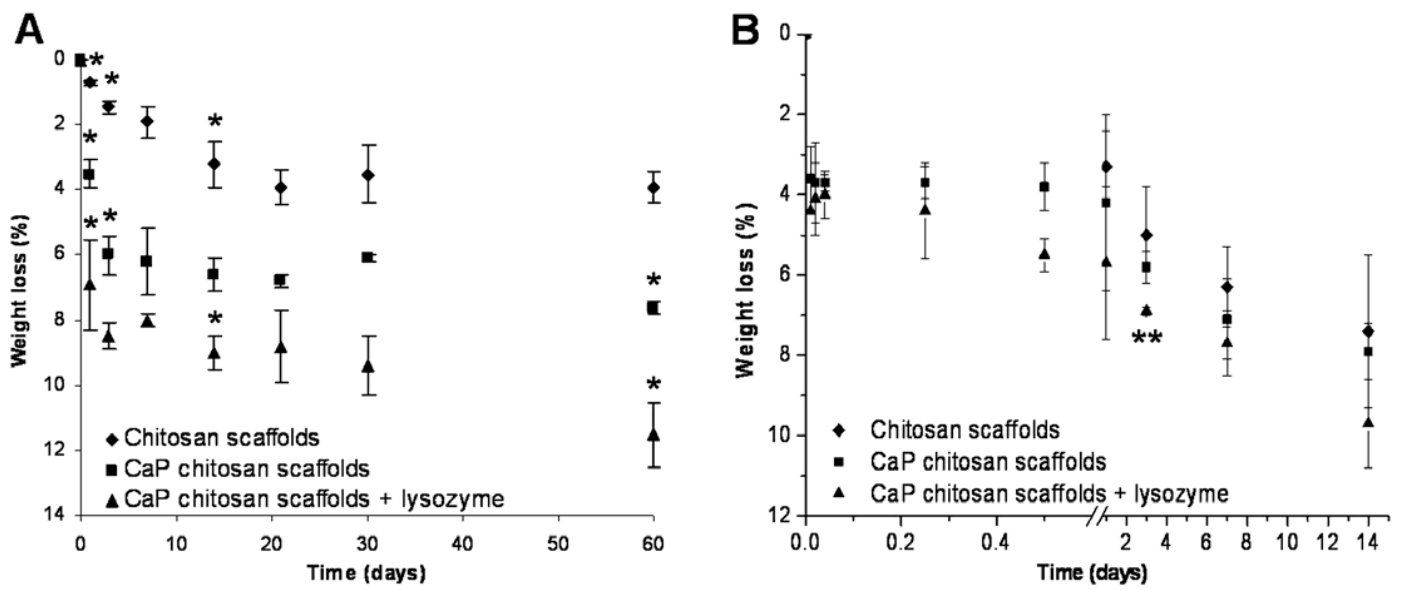

Fig. 3. Weight loss profile of uncoated chitosan scaffolds, CaP-coated chitosan scaffolds and CaP-coated chitosan scaffolds with incorporated lysozyme as a function of immersion time at (A) pH 7.4 and (B) pH 5. * Significant difference between time points for each condition. At pH 7.4, for each time point all differences between conditions are significant. ${ }^{* *}$ Significant difference between conditions at the same time point. The weight loss at pH 5 for chitosan scaffolds is significantly different when compared with that at $\mathrm{pH} 7.4$.

theless, immersion periods at $\mathrm{pH} 7.4$ up to 30 days induced roughness in the surface of uncoated chitosan scaffolds (Fig. 4D, G and J), and changes in the CaP coating morphology (in the case of CaP-coated chitosan scaffolds with and without incorporated lysozyme). However, all scaffolds were coated with a CaP layer, meaning that the coatings are quite stable at normal physiological $\mathrm{pH}$.

The results of degradation studies performed at $\mathrm{pH} 5$ are shown in Fig. 3B. The same trend was observed for the weight loss results at $\mathrm{pH}$ 7.4. Coated scaffolds with incorporated lysozyme exhibited a faster degradation rate, when compared with the other two conditions (uncoated chitosan and CaP-coated chitosan scaffolds) (Fig. 3B). This indicates the role of this enzyme on the hydrolysis of chitosan.
These results are confirmed by the results of enzyme activity at $\mathrm{pH} 5$, which show that lysozyme is active at that $\mathrm{pH}$ (Fig. 6B). Independent of the $\mathrm{pH}$, the presence of lysozyme seems to control the degradation rate of the scaffolds.

Analysing the SEM images of uncoated chitosan scaffolds after 14 days of degradation at $\mathrm{pH} 5$, it is possible to observe increased degradation with immersion time (Fig. 5A, D, G, J and M). After only 3 days, evident changes are observed on the surface of uncoated chitosan scaffolds (Fig. 6D). This appears to be related to the high susceptibility of chitosan at acidic pH. In Fig. 5E, H, K and $\mathrm{N}$, the images of CaP-coated chitosan scaffolds after different times at $\mathrm{pH} 5$ are presented. After $1 \mathrm{~h}$ almost all the CaP layer was dissolved (data not shown), and it was 

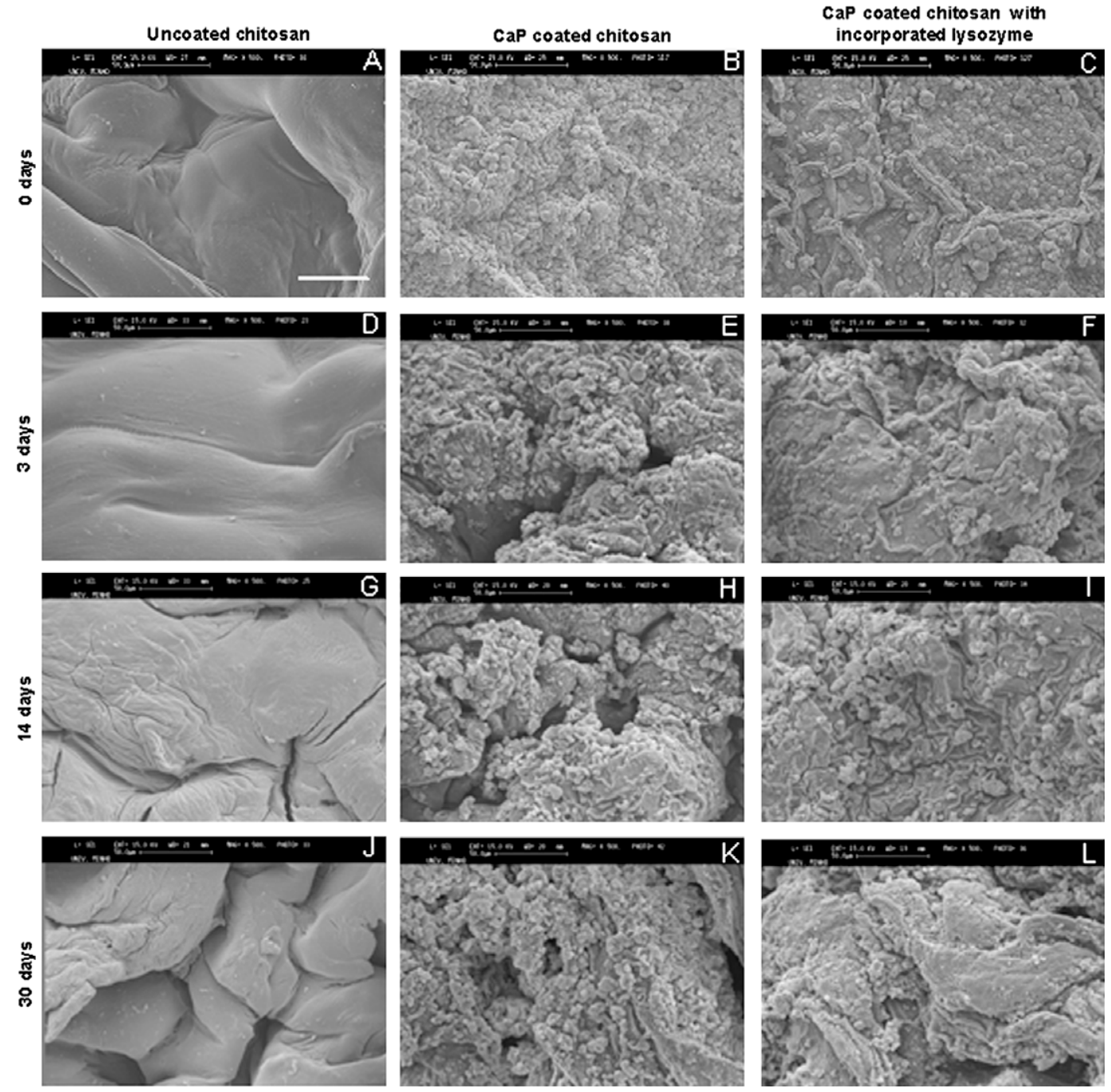

Fig. 4. SEM images of chitosan scaffolds, CaP chitosan scaffolds and CaP chitosan scaffolds with incorporated lysozyme before and after degradation at pH 7.4 up to 30 days. Scale bar is $50 \mu \mathrm{m}$ and applies to all images.

non-existent after 1 day of degradation (Fig. 5E). SEM images evidence the formation of pores after only 1 day, but the formation of interconnected pores is not clearly visible (Fig. 5E, H, K and N).

The most interesting results were obtained for CaPcoated scaffolds with incorporated lysozyme (Fig. 5F, I, $\mathrm{L}$ and $\mathrm{O}$ ). The degradation effect of lysozyme on chitosan is clearly visible from the emergence of a highly porous structure with time (Fig. 5F, I, L and O). After $1 \mathrm{~h}$, it is possible to observe a $\mathrm{CaP}$ layer on the surface of scaffolds (data not shown). However, after 1 day, as previously described, the dissolution of the coatings and pore formation as a function of degradation time was observed. In this case, the formation of pores is clearly visible after 7 days, with a structure having interconnected pores (Fig. $5 \mathrm{~L}$ and L1). After 14 days, the scaffolds exhibit pores with diameter of $\sim 50-300 \mu \mathrm{m}$ (Fig. 5O1). This pore formation is corroborated by the weight loss results. The CaP-coated chitosan scaffolds with incorporated lysozyme presented the highest weight loss. In addition, lysozyme activity measurements at $\mathrm{pH} 5$ showed that this enzyme is active.

The incorporation of lysozyme into CaP coatings, grown on the surface of chitosan scaffolds may be used as a strategy to control their degradation rate better. Both degradation studies ( $\mathrm{pH} 7.4$ and $\mathrm{pH} 5$ ) show that the presence of lysozyme enhanced the degradation of chitosan scaffolds. The $\mathrm{pH}$ of the degradation media has a remarkable influence on $\mathrm{CaP}$ coatings. At $\mathrm{pH} 7.4$, all scaffolds remained coated up to 60 days. However, at $\mathrm{pH} \mathrm{5}$, after 1 day, the dissolution of the coatings and formation of pores was observed mostly when due to the presence of lysozyme. These results show that lysozyme has an important role in the degradation of chitosan scaffolds. CaP-coated chitosan scaffolds with incorporated lysozyme presented the highest values of weight loss at both $\mathrm{pH} 7.4$ and $\mathrm{pH}$ 5. At pH 7.4, no effect of lysozyme on the scaffold morphology was evident. Nevertheless, it enhanced the formation of a porous structure with interconnected pores at $\mathrm{pH} 5$. 

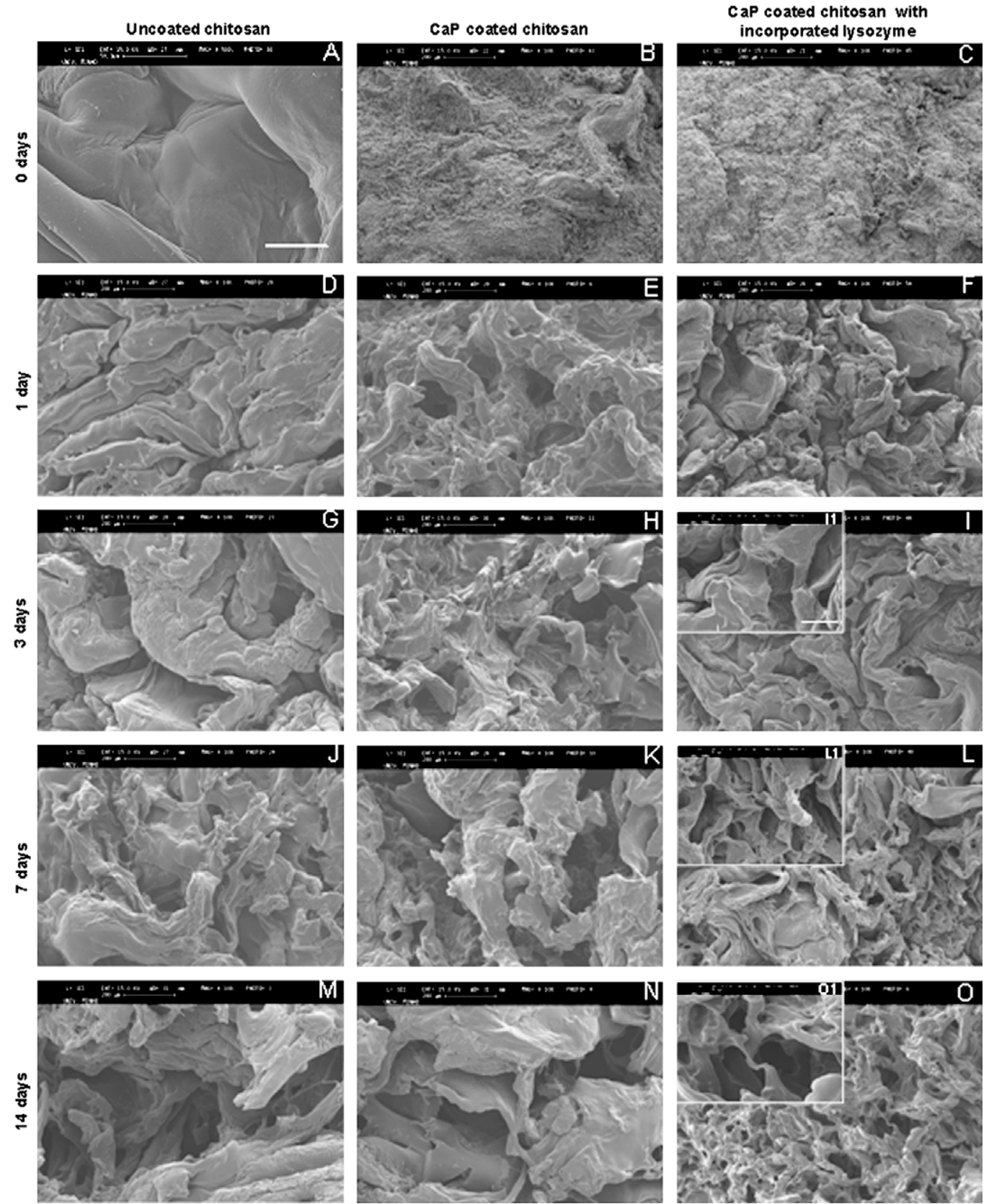

Fig. 5. SEM images of chitosan scaffolds, $\mathrm{CaP}$ chitosan scaffolds and $\mathrm{CaP}$ chitosan scaffolds with incorporated lysozyme before and after degradation at pH 5 up to 14 days. The scale bar is $200 \mu \mathrm{m}$ for all images except for I1, L1, O1 (50 $\mu \mathrm{m})$.

\subsection{Lysozyme activity in solution and released from the coatings}

Evaluation of the activity of the lysozyme released from the coatings (Fig. 6A) revealed that the enzyme was able to hydrolyze the peptidoglycan of the bacteria cell walls (as detected by the decrease in optical density with time). The results of this study (Fig. 6A) showed that the enzyme remained active after 30 days of immersion in buffer solution ( $\mathrm{pH}$ 7.4).

Changes in the $\mathrm{pH}$ of the environment can alter or inhibit enzyme activity. In order to confirm that lysozyme is active at both $\mathrm{pH} 5$ and $\mathrm{pH}$ 7.4, known lysozyme concentrations were used to construct a calibration curve. OD slopes were determined for different lysozyme concentrations (Fig. 6B) and an increase in enzymatic activity as a function of increasing lysozyme concentration was observed. Lysozyme is active at $\mathrm{pH} 5$ and $\mathrm{pH}$ 7.4. The OD slope for the first $5 \mathrm{~min}$ in the graph was also calculated (Fig. 6A) to determine the lysozyme activity released from the coatings. The activity of lysozyme released from the coatings was $0.0375 \mathrm{U}$ (1 U corresponds to the amount of enzyme which decreases the absorbance at $450 \mathrm{~nm} \mathrm{~min}{ }^{-1}$ at $\mathrm{pH} 7.4,37^{\circ} \mathrm{C}$ using a suspension of Micrococcus lysodeikticus as substrate). 
A

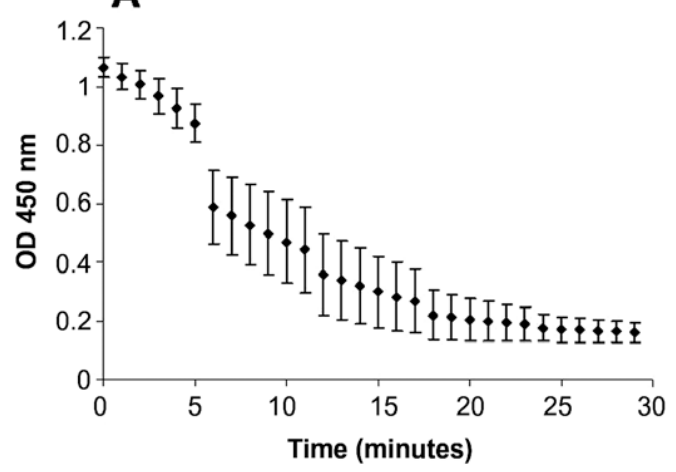

B

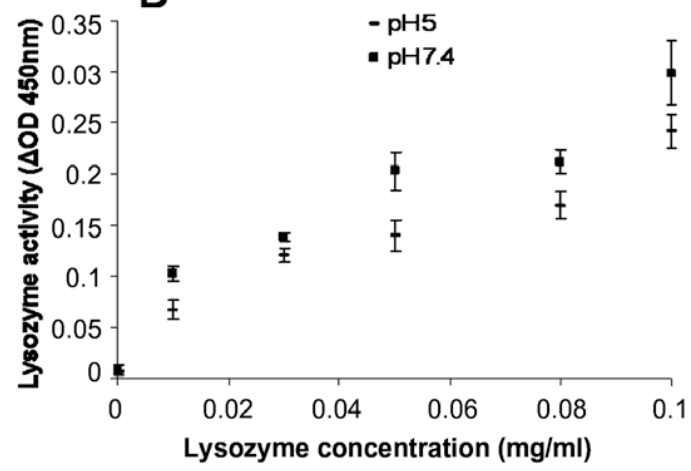

Fig. 6. (A) Lysozyme activity (measured as a decrease in the optical density of a Micrococcus lysodeikticus bacteria suspension) released from CaP coatings after immersion in buffer ( $\mathrm{pH} 7.4$ ) for 30 days and (B) lysozyme activity at $\mathrm{pH} 5$ and 7.4 as a function of lysozyme concentration.

\section{Conclusions}

In this work, lysozyme was successfully incorporated into $\mathrm{CaP}$ coatings produced on the surface of chitosan scaffolds, using a biomimetic technique. Degradation studies at pH 7.4 to simulate normal physiological conditions showed that the morphology of uncoated scaffolds and $\mathrm{CaP}$ coatings changed. However, the formation of pores as a function of immersion time was not observed. Moreover, CaP coatings are very stable at $\mathrm{pH} 7.4$ and, after 30 days, all scaffolds remained covered with a CaP layer. At $\mathrm{pH} 5$, to simulate an in vivo inflammatory response, a porous structure was formed when lysozyme was incorporated into the $\mathrm{CaP}$ coatings. The degradation effect of lysozyme on chitosan at pH 5 is clearly visible from the appearance of pores. In addition, at high magnifications, SEM images suggest that these pores are interconnected. It was also shown that lysozyme incorporated into the coatings was active after 30 days of immersion in buffer solution ( $\mathrm{pH}$ 7.4). This approach is very promising, as the presence of lysozyme incorporated into the coatings will allow chitosan scaffolds with gradual in vivo pore-forming ability and antibacterial properties that can simultaneously exhibit osteoconductive properties via the presence of $\mathrm{CaP}$ coating to be obtained.

\section{Acknowledgements}

This work was supported by the European NoE EXPERTISSUES (NMP3-CT-2004-500283), the European STREP HIPPOCRATES (NMP3-CT-2003-505758), the Portuguese Foundation for Science and Technology (FCT) through POCTI and/or FEDER programmes.

\section{References}

[1] Martins AM, Santos MI, Azevedo HS, Malafaya PB, Reis RL. Natural origin scaffolds with in situ pore forming capability for bone tissue engineering applications. Acta Biomaterialia 2008;4(6): $1637-45$.

[2] Chatelet C, Damour O, Domard A. Influence of the degree of acetylation on some biological properties of chitosan films. Biomaterials $2001 ; 22(3): 261-8$.
[3] Klokkevold PR, Vandemark L, Kenney EB, Bernard GW. Osteogenesis enhanced by chitosan (poly- $N$-acetyl glucosaminoglycan) in vitro. J Periodontol 1996;67(11):1170-5.

[4] Varum KM, Myhr MM, Hjerde RJ, Smidsrod O. In vitro degradation rates of partially $N$-acetylated chitosans in human serum. Carbohydr Res 1997;299(1-2):99-101.

[5] Tomihata K, Ikada Y. In vitro and in vivo degradation of films of chitin and its deacetylated derivatives. Biomaterials 1997;18(7):567-75.

[6] Hankiewi J, Swiercze E. Lysozyme in human body-fluids. Clin Chim Acta 1974;57(3):205-9.

[7] Porstmann B, Jung K, Schmechta H, Evers U, Pergande M, Porstmann T, et al. Measurement of lysozyme in human body fluids: comparison of various enzyme immunoassay techniques and their diagnostic application. Clin Biochem 1989;22(5):349-55.

[8] Proctor VA, Cunningham FE. The chemistry of lysozyme and its use as a food preservative and a pharmaceutical. Crit Rev Food Sci Nutr 1988;26(4):359-95.

[9] Torsteinsdottir I, Hakansson L, Hallgren R, Gudbjornsson B, Arvidson NG, Venge P. Serum lysozyme: a potential marker of monocyte/macrophage activity in rheumatoid arthritis. Rheumatology (Oxford) 1999;38(12):1249-54.

[10] Habibovic P, Li J, van der Valk CM, Meijer G, Layrolle P, van Blitterswijk CA, et al. Biological performance of uncoated and octacalcium phosphate-coated Ti6A14V. Biomaterials 2005;26(1): 23-36.

[11] Liu Y, de Groot K, Hunziker EB. BMP-2 liberated from biomimetic implant coatings induces and sustains direct ossification in an ectopic rat model. Bone 2005;36(5):745-57.

[12] Habobovic P, de Groot K. Osteoinductive biomaterials-properties and relevance in bone repair. J Tissue Eng Regen Med 2007;1(1):25-32.

[13] Abe Y, Kokubo T, Yamamuro T. Apatite coating on ceramics, metals and polymers utilizing a biological process. J Mater Sci Mater Med 1990;1(4):233-8.

[14] Reis RL, Cunha AM, Fernandes MH, Correia RN. Treatments to induce the nucleation and growth of apatite-like layers on polymeric surfaces and foams. J Mater Sci Mater Med 1997; 8(12):897-905.

[15] Oliveira AL, Elvira C, Reis RL, Vazquez B, San Roman J. Surface modification tailors the characteristics of biomimetic coatings nucleated on starch-based polymers. J Mater Sci Mater Med 1999;10(12):827-35.

[16] Tuzlakoglu K, Reis RL. Formation of bone-like apatite layer on chitosan fiber mesh scaffolds by a biomimetic spraying process. J Mater Sci Mater Med 2007;18(7):1279-86.

[17] Ohtsuki C, Kamitakahara M, Miyazaki T. Coating bone-like apatite onto organic substrates using solutions mimicking body fluid. J Tissue Eng Regen Med 2007;1(1):33-8.

[18] Campbell AA. Bioceramics for implant coatings. Mater Today 2003;6(11):26-30. 
[19] Leonor IB, Azevedo HS, Alves CM, Reis RL. Effects of protein incorporation on calcium phosphate coating. Mater Sci Eng C Mater Biol Appl 2009;29:913-8.

[20] Liu Y, Hunziker EB, Randall NX, de Groot K, Layrolle P. Proteins incorporated into biomimetically prepared calcium phosphate coatings modulate their mechanical strength and dissolution rate. Biomaterials 2003;24(1):65-70.

[21] Liu Y, Hunziker EB, Layrolle P, De Bruijn JD, De Groot K. Bone morphogenetic protein 2 incorporated into biomimetic coatings retains its biological activity. Tissue Eng 2004;10(1-2):101-8.

[22] Azevedo HS, Leonor IB, Alves CM, Reis RL. Incorporation of proteins and enzymes at different stages of the preparation of calcium phosphate coatings on a degradable substrate by a biomimetic methodology. Mater Sci Eng C Biomimetic Supramol Syst 2005;25(2):169-79.

[23] Atala A. Engineering tissues, organs and cells. J Tissue Eng Regen Med 2007;1(2):83-96.

[24] Tuzlakoglu K, Alves CM, Mano JF, Reis RL. Production and characterization of chitosan fibers and 3-D fiber mesh scaffolds for tissue engineering applications. Macromol Biosci 2004;4(8):811-9.

[25] Xie J, Riley C, Kumar M, Chittur K. FTIR/ATR study of protein adsorption and brushite transformation to hydroxyapatite. Biomaterials 2002;23(17):3609-16.

[26] Mann S. Biomineralization. Principles and concepts in bioinorganic materials chemistry. Oxford: Oxford University Press; 2001. 